\title{
Exhaled carbon monoxide and inducible heme oxygenase expression in a rat model of postperfusion acute lung injury
}

\author{
Rachid Zegdi, $\mathrm{MD}^{\mathrm{a}}$ \\ Olivier Fabre, MD \\ Nermine Lila, DVM ${ }^{\mathrm{a}}$ \\ Paul Fornès, $\mathrm{PhD}^{\mathrm{b}}$ \\ Michèle Cambillau, PhD ${ }^{b}$ \\ Ming Shen, $\mathrm{PhD}^{\mathrm{a}}$ \\ Philippe Hervé, $\mathrm{MD}^{\mathrm{c}}$ \\ Alain Carpentier, $\mathrm{PhD}^{\mathrm{b}}$ \\ Jean-Noël Fabiani, $M D^{b}$
}

From the Laboratoire d'Etudes des Greffes et Prothèses Cardiaques, ${ }^{a}$ Hôpital Broussais, Paris, France; Hôpital Européen Georges Pompidou, ${ }^{\mathrm{b}}$ Paris, France; and Hôpital Marie-Lannelongue, ${ }^{\mathrm{C}}$ Le Plessis-Robinson, France

This work was supported by: Laboratoires L. Lafon, Créteil, France.

Received for publication May 10, 2002; revisions requested Sept 3, 2002; revisions received May 15, 2003; accepted for publication June 18, 2003.

Address for reprints: Dr Rachid Zegdi, Hôpital Européen Georges Pompidou, Service de Chirurgie Cardiovasculaire, 20, rue Leblanc 75908 Paris France (E-mail: rzegdi@hotmail.com).

J Thorac Cardiovasc Surg 2003;126: 1867-74

Copyright $(\odot) 2003$ by The American Association for Thoracic Surgery

$0022-5223 / 2003 \$ 30.00+0$

doi:10.1016/S0022-5223(03)01310-2
Objective: Expression of inducible heme oxygenase has been shown to be increased in various visceral inflammatory disorders, which may confer a protective role. The purpose of our study was to determine whether the expression of inducible heme oxygenase was up-regulated within lungs in a rat model of extracorporeal circulation.

Methods: Wistar rats underwent either a partial femoro-femoral extracorporeal circulation in normothermia for 3 hours $(n=5)$ or a sham procedure $(n=5)$. Exhaled carbon monoxide concentration was monitored with an infrared analyzer. After the rats were killed, lungs were harvested for determination of heme oxygenase activity and inducible heme oxygenase expression (by Western blot and immunohistochemistry). Lung injury was also assessed by arterial blood gas analysis and microscopic study.

Results: Extracorporeal circulation was responsible for a lung injury characterized by decreased arterial blood oxygen saturation and typical morphologic findings (marked alveolar neutrophil infiltration; interstitial edema). Exhaled carbon monoxide concentration remained stable throughout the experiment in all sham rats, whereas it increased after extracorporeal circulation (from $0.16 \pm 0.05 \mathrm{ppm}$ at baseline to $0.7 \pm 0.2 \mathrm{ppm}$ at end of experiment; $P=.0001)$. Pulmonary heme oxygenase activity and inducible heme oxygenase content (assessed by Western blot) were increased within lungs of rats that underwent extracorporeal circulation. Immunohistochemistry revealed that the expression of inducible heme oxygenase was mainly localized to inflammatory cells.

Conclusions: Post-extracorporeal circulation acute lung injury in rats was associated with an increased expression of inducible heme oxygenase, the functional significance of which remains to be determined.

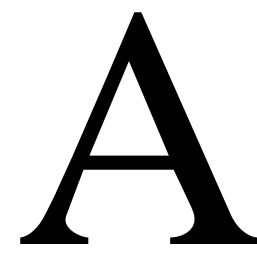

cute lung injury (ALI) is a potential complication of cardiac surgery with extracorporeal circulation (ECC). The most severe forms are clinically easily recognizable with a reported incidence of $0.5 \%$ to $1.7 \%$ and a mortality rate ranging from $50 \%$ to 91.6\%. ${ }^{1,2}$ However, in morphologic studies, ALI appeared to affect most, if not all, patients shortly after cardiac surgery. ${ }^{3,4}$ Because there is no method available to detect and monitor the pulmonary inflam- 
matory insult noninvasively, the impact of milder forms of postperfusion ALI on the postoperative morbidity and mortality remains unknown.

Carbon monoxide is synthesized in mammalians, mainly from heme degradation. ${ }^{5}$ Endogenously produced $\mathrm{CO}$ does not accumulate within the body and is excreted in exhaled breath. ${ }^{6}$ Heme oxygenase (HO) is the step-limiting enzyme from heme catabolism. Three isoforms of $\mathrm{HO}$ have been described, 1 inducible (HO1) and 2 constitutive (HO2 and HO3). These isoforms differ by their cellular location and the regulation of their expression. ${ }^{7} \mathrm{HO} 1$ isoform has been shown to be primarily induced during oxidative injury. ${ }^{8}$ Increased expression of $\mathrm{HO} 1$ has also been described in a few experimental models of ALI, which was associated with a protective role. ${ }^{9}$

The primary purpose of this study was to determine the influence of extracorporeal circulation on the expression of HO1 in postperfusion ALI by using a previously described rat model of partial bypass. ${ }^{10} \mathrm{We}$ also evaluated the impact of extracorporeal circulation on the endogenous $\mathrm{CO}$ production by measuring blood carboxyhemoglobin concentration and monitoring exhaled $\mathrm{CO}$ concentration.

\section{Materials and Methods}

The study was approved by the local Institutional Animal Care and Use Committee and all animals were treated according to the European regulations for animal experimentation. ${ }^{11}$

\section{Extracorporeal Circulation}

Circuit preparation. The ECC circuit consisted of a nonpulsatile roller pump (Jouvelet, Simal, Paris, France) and sterile Tygon tubing with an inner diameter of $2.4 \mathrm{~mm}$ for the venous line and $0.8 \mathrm{~mm}$ for the arterial line (Masterflex R3603, Bioblock Scientific, Illkirch, France). ECC was established at a flow rate of $100 \mathrm{~mL} / \mathrm{kg} / \mathrm{min}$. Venous return was drained by gravity into a 20-mL sterile reservoir. The membrane oxygenator obtained from Capiox 308 (Terumo, Osaka, Japan) is commonly used in pediatric cardiac surgery. To reduce the prime volume of the oxygenator $(110 \mathrm{~mL})$, we removed the heat exchanger and placed at each extremity of the membrane 2 silicone "cones" specifically designed for the experiment. These cones excluded approximately $75 \%$ of the total membrane surface area from circulation. The total prime volume of the circuit was $35 \mathrm{~mL}$ of which the oxygenator constituted $15 \mathrm{~mL}$. The priming was done with $20 \mathrm{~mL}$ of fresh blood obtained from 2 homologous donor rats and with $15 \mathrm{~mL}$ of synthetic colloid (Plasmion, Frésénius, France). Gas flow (100\% $\mathrm{O}_{2}$ ) was maintained between 50 and $75 \mathrm{~mL} / \mathrm{min}$. Preliminary experiments have shown that this gas flow was sufficient to achieve adequate oxygenation. ${ }^{10}$

Surgical procedure. Male Wistar rats $(475-550 \mathrm{~g})$ were used for all experiments. They were anesthetized with an intramuscular administration of ketamine hydrochloride $(80 \mathrm{mg} / \mathrm{kg})$ and chlorpromazine hydrochloride $(2 \mathrm{mg} / \mathrm{kg})$. Anesthesia was maintained throughout the experiment with additional doses of intravenous ketamine. Sustained muscle relaxation was achieved with an intravenous injection of $1 \mathrm{mg} / \mathrm{kg}$ of pancuronium bromide. Rats were continuously ventilated through a tracheostomy with air at 80 breaths $/ \mathrm{min}$ and $8 \mathrm{~mL} / \mathrm{kg}$ tidal volume under $4 \mathrm{~cm} \mathrm{H}_{2} \mathrm{O}$ positive end-expiratory pressure (Harvard Rodent Respirator, model 680, SARL Ealing, Ulis, France). Central temperature was monitored with an esophageal probe and maintained between $36^{\circ} \mathrm{C}$ and $38^{\circ} \mathrm{C}$ by a heating lamp placed above the animal and the oxygenator. The tail artery was cannulated (25-gauge Teflon catheter; Ethicon, Issy les Moulineaux, France) to monitor systemic arterial pressure (Hewlett Packard, model 78342A; Hewlett Packard Company, Palo Alto, Calif). The right femoral vein and artery were exposed and cannulated with 16- and 25-gauge Teflon heparinized catheters, respectively. Anticoagulation consisted of heparin (500 IU/ $\mathrm{kg}$ ), which was administered in the following manner: half the dosage was given to the blood donor rats and a quarter of the dosage was added to the priming volume and to the study rat.

\section{Protocol}

Rats were assigned to either an ECC group or a sham group. Both the ECC and sham groups consisted of 5 rats. Anesthesia, ventilation, cannulation, and heparinization were identical in both groups throughout the experiment. Connection to the extracorporeal circuit was only performed in the ECC group. Ventilation was not discontinued during the ECC period. ECC lasted for 3 hours and rats were further monitored for another 3 hours before they were killed. After cessation of the ECC, rats were infused with the remaining priming medium when diastolic pressure was less than $50 \mathrm{~mm} \mathrm{Hg}$. Arterial blood gas analysis was performed before the start of ECC (baseline) and at the end of the experiment.

Rats were killed by exsanguination. They were then perfused with $500 \mathrm{~mL}$ of cold saline $\left(4^{\circ} \mathrm{C}\right)$. Lungs were harvested without the trachea and the proximal bronchi. The left lung was immersed in $4 \%$ neutral buffered formalin for 48 hours. The right lung was homogenized in a buffer containing $50 \mathrm{mmol} / \mathrm{L}$ Tris- $\mathrm{HCl}(\mathrm{pH} 7.4)$, $250 \mathrm{mmol} / \mathrm{L}$ sucrose, and 1 tablet (per $50 \mathrm{~mL}$ ) of an antiprotease mixture (Complete; Boehringer Mannheim, Meylan, France). The homogenate was centrifuged at $10,000 \mathrm{~g}$ for 20 minutes and the supernatant was collected and stored at $-80^{\circ} \mathrm{C}$. Protein concentration was determined by the modified Peterson method.

\section{Measurement of Exhaled Carbon Monoxide Concentration}

Exhaled $\mathrm{CO}$ was measured using an infrared $\mathrm{CO}$ analyzer $(\mathrm{CO}$ 2000; Sérès, La Duranne, France). The CO analyzer was calibrated prior to each experiment with a $\mathrm{CO}$ calibration gas at a concentration of $10.3 \mathrm{ppm}$ (Air Liquide, Bonneuil, France). Its sensitivity was $0.1 \mathrm{ppm}$ and its sampling rate was set at $1 \mathrm{~L} / \mathrm{min}$.

All rats were ventilated with $\mathrm{CO}$-free rendered air ( $\mathrm{CO}$ concentration $\leq 0.1 \mathrm{ppm}$ ) by its passage through a heated hopcalite filter (Sérès). Expired breath was collected into a 6-L polyethylene bag that did not react with $\mathrm{CO}$. The bag was placed at the expiratory outlet of the ventilator and was rapidly connected to the $\mathrm{CO}$ analyzer when filled. Each gas collection lasted approximately 20 minutes. Therefore, measurements indicated at each time point represent the mean exhaled $\mathrm{CO}$ concentration of gas collected over the preceding 20 minutes. Exhaled CO concentration was determined before (baseline), during (30, 90, and 180 minutes), and after cessation (1,2, and 3 hours) of ECC. 


\section{Heme Oxygenase Activity}

The method was derived from Tenhunen and colleagues. ${ }^{12}$ Briefly, as a source of biliverdin reductase, livers from fasted rats were harvested and immediately placed in cold $0.9 \% \mathrm{NaCL}$. The livers were then weighed and homogenized in 4 volumes of $2 \mathrm{mmol} / \mathrm{L}$ $\mathrm{MgCl}_{2}-100 \mathrm{mmol} / \mathrm{L}$ phosphate buffer ( $\left.\mathrm{pH} 7.4\right)$. The homogenate was centrifuged at $105,000 \mathrm{~g}$ for 1 hour at $4^{\circ} \mathrm{C}$ and the supernatant (liver cytosol) was used as a source of biliverdin reductase.

The reaction mixture consisted of $200 \mu \mathrm{L}$ of lung supernatant, $50 \mu \mathrm{L}$ of liver cytosol, $20 \mu \mathrm{L}$ of $1 \mathrm{mmol} / \mathrm{L}$ heme b solution, 200 $\mu \mathrm{L}$ of $2.75 \mathrm{mmol} / \mathrm{L} \beta$-nicotinamide adenine dinucleotide phosphate (NADPH) solution, and $530 \mu \mathrm{L}$ of $2 \mathrm{mmol} / \mathrm{L} \mathrm{MgCl}_{2}-100$ $\mathrm{mmol} / \mathrm{L}$ phosphate buffer ( $\mathrm{pH}$ 7.4). The samples were incubated in a $37^{\circ} \mathrm{C}$ water bath in the dark for 1 hour. The reaction was stopped by placement on ice. An NADPH-free reaction mixture provided a baseline against which the measured concentrations were compared. The absorbance of the samples was measured by spectrophotometry (model DU-70; Beckman, Villepinte, France) at 464 and $530 \mathrm{~nm}$. The amount of bilirubin formed was calculated from the difference in optical density at 464 and $530 \mathrm{~nm}$, assuming an extinction coefficient of $40 \mathrm{mmol} / \mathrm{L}^{-1} \cdot \mathrm{cm}^{-1}$. The values are expressed as picomoles of bilirubin formed per milligram of protein per hour.

\section{HO1 Detection by Western Blot}

An aliquot of homogenate was suspended in sodium dodecylsulphate (SDS) sample buffer $(125 \mathrm{mmol} / \mathrm{L}$ Tris- $\mathrm{HCl}[\mathrm{pH}=7.4]$, $10 \%$ glycerol, $6 \%$ SDS, $0.01 \% \beta$-mercaptoethanol, and $0.1 \%$ bromophenol blue). Equal amounts of protein per lane $(150 \mu \mathrm{g})$ were subjected to electrophoresis in a $12 \%$ SDS-polyacrylamide gel. Gels were transferred onto nitrocellulose membranes by electroblotting. The membranes were blocked by incubation in phosphate-buffered saline solution (PBS) 1X, 5\% nonfat dry milk, and $0.2 \%$ Tween 20 for 1 hour at room temperature. Blots were then incubated overnight at $4^{\circ} \mathrm{C}$ in the same buffer containing a rabbit polyclonal antibody against rat $\mathrm{HO} 1$ (1:1,000; Tebu, France). Blots were washed 4 times for 15 minutes in PBS $1 \mathrm{X}$ and $0.2 \%$ Tween 20 and thereafter incubated with horseradish peroxidase-conjugated goat anti-rabbit immunoglobulin $\mathrm{G}(\mathrm{IgG})$ secondary antibody (1:15,000; Amersham, Orsay, France). Blots were then washed and immunoreactivity was assessed using an enhanced Western blot detection system according to the manufacturer's protocol (Amersham). Spleen homogenates were used as positive controls for $\mathrm{HO} 1$.

\section{Histology}

After fixation, the left lung was embedded in paraffin. Two sections of $3-\mu \mathrm{m}$ thickness were obtained from each block and stained with hematoxylin-eosin.

\section{Immunohistochemistry}

Tissue sections were deparaffinized in xylene and then rehydrated in graded alcohol solutions. The sections were blocked in a solution of $5 \%$ nonfat milk, $1 \%$ bovine serum albumin (BSA) before incubation overnight at $4{ }^{\circ} \mathrm{C}$ with a rabbit polyclonal antibody to HO1 (Tebu, Le Perray, France) in $1 \%$ milk and $1 \%$ BSA in PBS $1 \mathrm{X}$ (1:1,000 dilution). The sections were washed 3 times with PBS for 5 minutes each and incubated for 1 hour with secondary antibody (biotinylated goat anti-mouse IgG; Jackson Laboratories, L'arbresle, France) at a dilution of 1:500 in 1\% milk, PBS $1 \mathrm{X}$ at room temperature. The signal was detected with peroxidase-conjugated avidin and diaminobenzidine. The slides were counterstained with $1 \%$ hematoxylin. For negative controls, sections were processed as above except that the primary incubation was performed with nonimmune rabbit serum (Jackson Laboratories) instead of primary antibody.

\section{Blood Gas Analysis}

Arterial blood gas analysis, $\mathrm{pH}$, hematocrit, and carboxyhemoglobin were determined with a calibrated blood gas analyzer (ABL 505; Radiometer, Copenhagen, Denmark) and a CO oximeter (OSM 3, Radiometer).

\section{Determination of Bilirubin and Hemoglobin Plasmatic Concentration}

Measurement of total bilirubin plasmatic concentration was performed by using an automated colorimetric method (Synchron CX7; Beckman Coulter, Villepinte, France). Hemoglobin concentration was assessed spectrophotometrically by measuring the absorbance of the samples at 561 and $576 \mathrm{~nm}$ (DU70, Beckman Coulter).

\section{Statistics}

Results are expressed as mean \pm standard deviation. Comparisons of continuous data between sham and ECC groups were performed with the Mann-Whitney test.

\section{Results}

All rats completed the study. Baseline mean arterial blood pressure was $122 \pm 18 \mathrm{~mm} \mathrm{Hg}$ in the sham group and 118 $\pm 10 \mathrm{~mm} \mathrm{Hg}$ in the ECC group $(P=.8288)$. Mean arterial blood pressure remained stable throughout the experiment and did not differ between the 2 groups at any time (data not shown).

There was no difference in baseline arterial blood gas values between ECC and sham groups (Table 1). ECC was associated with a significant decrease in arterial oxygenation $\left(\mathrm{SaO}_{2}=80.8 \% \pm 11.9 \%\right.$ in the ECC group $\mathrm{vs}_{\mathrm{SaO}_{2}}=$ $95.5 \% \pm 3.7 \%$ in the sham group at the end of the experiment; $P=.009$ ).

Histologically, rats from the ECC group had pulmonary lesions consisting of interstitial edema and large areas of marked intravascular, interstitial, and intra-alveolar neutrophil and macrophage infiltration (Figure 1). There were also areas of alveolar hemorrhage. Conversely, only scattered and rare neutrophils were found within the lungs in the sham rats (Figure 1).

Baseline exhaled $\mathrm{CO}$ concentration was $0.14 \pm 0.05$ ppm in the sham group and $0.16 \pm 0.05 \mathrm{ppm}$ in the ECC group $(P=.5485)$. Exhaled $\mathrm{CO}$ concentration remained stable throughout the experiment in sham rats (Figure 2). In the ECC group, exhaled $\mathrm{CO}$ concentration started to increase between 90 and 180 minutes of ECC. Three hours after ECC discontinuation, exhaled $\mathrm{CO}$ concentration 
TABLE 1. Biological study of post-extracorporeal circulation (ECC) acute lung injury in rats

\begin{tabular}{lccc}
\hline & Sham $(\mathbf{n}=\mathbf{5})$ & ECC $(\mathbf{n}=\mathbf{5})$ & $\boldsymbol{P}$ value \\
\hline Blood gas analysis & & & \\
Baseline & & & \\
$\mathrm{PaO}_{2}(\mathrm{~mm} \mathrm{Hg})$ & $88 \pm 17.5$ & $85.2 \pm 12.6$ & .9168 \\
$\mathrm{SaO}_{2}(\%)$ & $95.1 \pm 4.1$ & $95 \pm 3.2$ & .9168 \\
$\mathrm{PcO}_{2}(\mathrm{~mm} \mathrm{Hg})$ & $36.6 \pm 7.2$ & $40.4 \pm 4.9$ & .3472 \\
$\mathrm{pH}$ & $7.45 \pm 0.45$ & $7.45 \pm 0.49$ & .9999 \\
$\mathrm{Ht}(\%)$ & $43.4 \pm 2.1$ & $41.6 \pm 4.2$ & .5271 \\
$\mathrm{HbCO}(\%)$ & $1.78 \pm 0.15$ & $1.86 \pm 0.3$ & .4592 \\
End of experiment & & & \\
$\mathrm{PaO}_{2}(\mathrm{~mm} \mathrm{Hg})$ & $95.6 \pm 11.3$ & $73.2 \pm 13.8$ & .0361 \\
$\mathrm{SaO}_{2}(\%)$ & $95.5 \pm 3.7$ & $80.8 \pm 11.9$ & .009 \\
$\mathrm{Pco}_{2}(\mathrm{~mm} \mathrm{Hg})$ & $37.4 \pm 5.4$ & $38.4 \pm 4.4$ & .6742 \\
$\mathrm{pH}$ & $7.45 \pm 0.1$ & $7.39 \pm 0.05$ & .1745 \\
$\mathrm{Ht}(\%)$ & $41.4 \pm 3.2$ & $41.2 \pm 1.8$ & .9147 \\
$\mathrm{HbCO}(\%)$ & $1.84 \pm 0.15$ & $2.34 \pm 0.56$ & .2031 \\
Bilirubin concentration & $6.6 \pm 1.3$ & $16.8 \pm 3.4$ & .0086 \\
$(\mu \mathrm{mol} / \mathrm{L})$ & & & \\
Free hemoglobin & $151.8 \pm 30.2$ & $341.2 \pm 295.5$ & .0278 \\
concentration (mg/L) & & & \\
& $149.7(130-205)^{*}$ & $274.3(152-864)^{*}$ & \\
\hline
\end{tabular}

$\mathrm{HbCO}$, Carboxyhemoglobin.

*Median (range).

reached a peak value that was significantly higher than baseline value $(0.7 \pm 0.2 \mathrm{ppm}$ at end of experiment vs 0.16 $\pm 0.05 \mathrm{ppm}$ at baseline; $P=.0001$ ).

Blood carboxyhemoglobin concentration was not significantly different between the 2 experimental groups at baseline and at end of experiment (Table 1). However, the variation of carboxyhemoglobin concentration (end of experiment concentration minus baseline concentration) was significantly higher in the ECC group $(0.46 \% \pm 0.25 \%$ in the ECC group vs $0.06 \% \pm 0.11 \%$ in the sham group; $P=$ .0144). Bilirubin concentration was significantly lower in the sham group at the end of experiment $(6.6 \pm 1.3 \mathrm{mmol} / \mathrm{L}$ in the sham group vs $16.8 \pm 3.4 \mathrm{mmol} / \mathrm{L}$ in the ECC group; $P=$.0086). Free hemoglobin concentration at the end of experiment was also significantly lower in the sham group (Table 1).

$\mathrm{HO}$ activity was significantly higher in the rat lungs from the ECC group ( $485 \pm 64.3 \mathrm{pmol} / \mathrm{mg}$ protein/h in the ECC group vs $178.8 \pm 29.1 \mathrm{pmol} / \mathrm{mg}$ protein $/ \mathrm{h}$ in the sham group; $P=.009$ ). Likewise, there was a statistically significant difference between the 2 groups regarding the spleen $\mathrm{HO}$ activity (Figure 3 ).

Western blot analysis revealed an increased $\mathrm{HO} 1$ protein content within lungs of the rats from the ECC group with respect to those from the sham group (Figure 4). Immunohistochemical studies revealed a marked expression of $\mathrm{HO} 1$ in neutrophils and macrophages infiltrating the rat lungs of the ECC group. A mild expression of $\mathrm{HO} 1$ was sometimes observed in airway epithelial cells. Conversely, no staining was found in the rat lungs from the sham group (Figure 5).

\section{Discussion}

In this study, we demonstrated that a 3-hour ECC in rats was responsible for an ALI. This inflammatory condition was associated with an increase in $\mathrm{HO} 1$ expression and $\mathrm{CO}$ concentration.

Based on the histological study (Figure 1), ECC in rats was clearly responsible for a diffuse inflammatory disorder of the lungs, which resembles the lung injury of other models of ALI. Moreover, the morphological findings in this rat model of post-ECC ALI were close to those previously described in larger animals (pig, dog, sheep) and in humans. ${ }^{3,4}$ In a previous study, we also observed an increase in lung water content (reflecting pulmonary edema) and in Evans blue dye content (an index of microvascular permeability) in lungs of rats that underwent a 90-minute ECC. ${ }^{13}$

We chose to cannulate the femoral vessels to prevent the lung injury that might have occurred with a thoracic approach. Our rat model of ECC was a partial bypass, with a pump flow approximately equivalent to half of the theoretical rat cardiac output. Ventilation, therefore, could not be discontinued during ECC. Rats that underwent ECC survived without any evident sequela. ${ }^{10} \mathrm{We}$ believe that our rat model of partial bypass is appropriate to investigate the pathophysiology and the natural course of postperfusion ALI.

Carbon monoxide in the body originates from an endogenous source and an exogenous source. Ambient CO represents the exogenous source. Mammalian cells synthesize CO (mainly from heme catabolism), which represents the endogenous source. ${ }^{6}$ Endogenously produced $\mathrm{CO}$ does not accumulate within the body. A small amount of $\mathrm{CO}$ is oxidatively transformed into carbon dioxide at a rate of $0.1 \%$ to $0.2 \%$ of the CO body content per hour. The bulk of synthesized CO is transported by blood (as carboxyhemoglobin) to the lungs where it is excreted in exhaled breath. Lung excretion is considered as the quasi-exclusive way of $\mathrm{CO}$ elimination from the body. This pulmonary excretion depends on many variables such as alveolar ventilation, $\mathrm{CO}$ lung diffusing capacity, lung capillary oxygen partial pressure, carboxyhemoglobin concentration, and endogenous CO production. ${ }^{14}$

In the present study, we demonstrated for the first time an increase in exhaled CO concentration after ECC. The concomitant increase in carboxyhemoglobin concentration (the largest $\mathrm{CO}$ store within the body) suggests that the increased exhaled $\mathrm{CO}$ reflects an increased endogenous $\mathrm{CO}$ production. Systemic hemolysis is known to increase the endogenous CO production and the exhaled CO concentration. ${ }^{15,16}$ Hemolysis occurred in our rat model of bypass (Table 1). In 

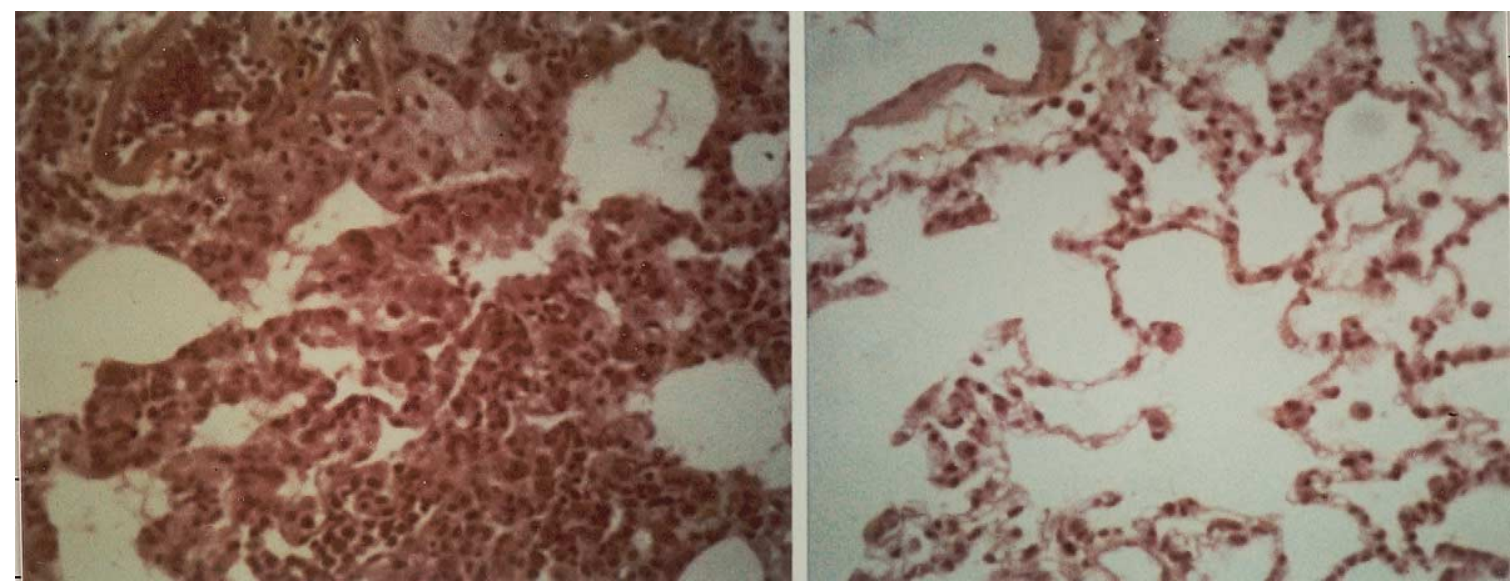

Figure 1. (Left) Acute lung injury in a rat that underwent a 3-hour extracorporeal circulation. Numerous macrophages and neutrophils infiltrating the interstitium and the alveolar spaces are visible. Stain: hematoxylin-eosin; original magnification $\times 400$. (Right) Histology of a sham rat's normal lung. Stain: hematoxylin-eosin; original magnification $\times 400$.

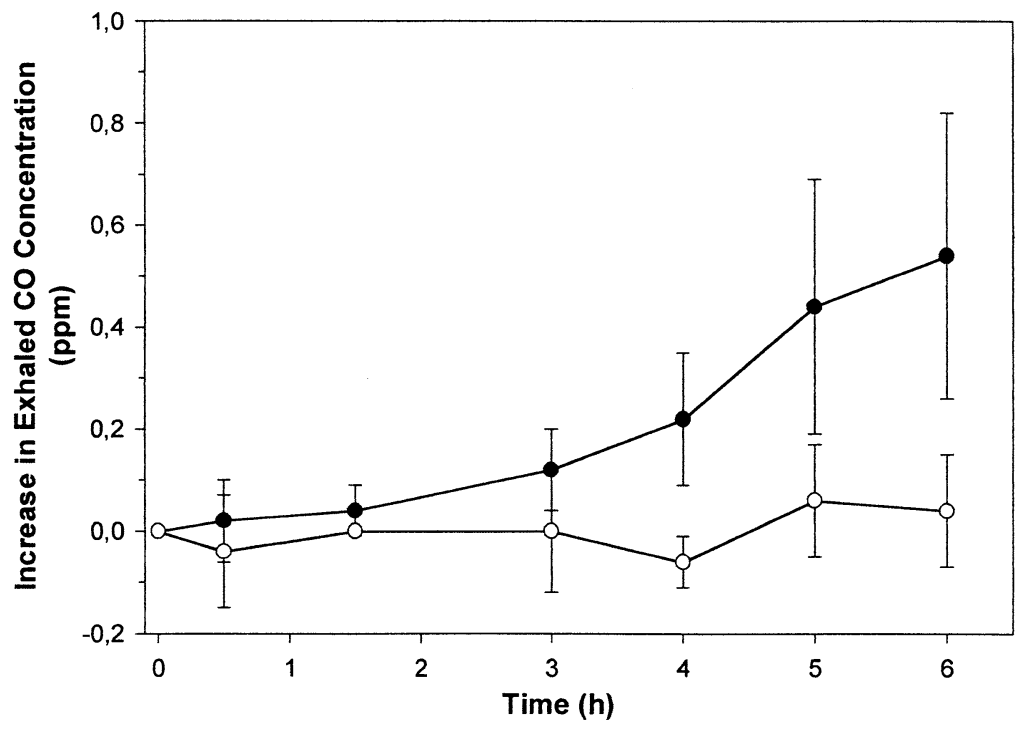

Figure 2. Comparative evolution of the increase in exhaled carbon monoxide (CO) concentration of rats that underwent a 3-hour extracorporeal circulation (ECC) (closed circles) compared with rats that did not (open circles). Exhaled $\mathrm{CO}$ concentration remained unchanged in the sham group whereas it significantly increased in the ECC group.

addition to hemolysis, other processes may explain the increased endogenous $\mathrm{CO}$ production during ECC, such as an exaggerated turnover of hemoproteins other than hemoglobin (such as cytochromes, peroxidases) or the production of CO secondary to lipid peroxidation. ${ }^{5}$

Elevated CO concentrations in exhaled breath have recently been reported in various bronchopulmonary inflammatory disorders such as asthma, ${ }^{17}$ bronchiectasis,${ }^{18}$ or cystic fibrosis. $^{19}$ This increased exhaled $\mathrm{CO}$ has been demonstrated to reflect the severity of the inflammatory process in some instances. ${ }^{17} \mathrm{We}$ are not aware of any study dealing with exhaled $\mathrm{CO}$ measurement in experimental or clinical ALI. Based on our study, it seems unlikely that monitoring exhaled $\mathrm{CO}$ will help noninvasive assessment of the severity of the inflammatory process in postperfusion ALI, as long as hemolysis persists.

In a recent study, we observed an increased heme oxygenase activity in lungs from rats that underwent a 90- 


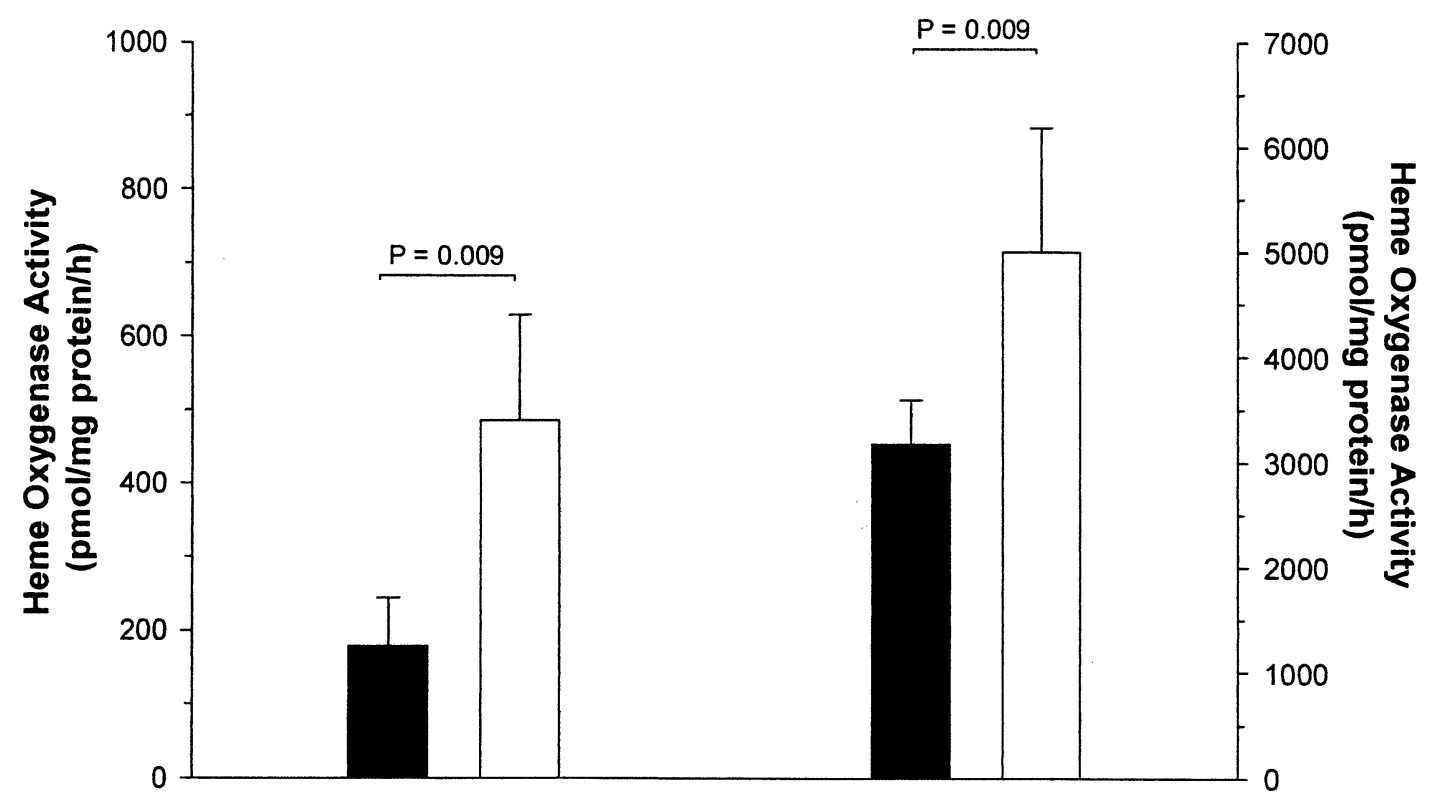

Figure 3. Comparison of heme oxygenase activity in lung (left panel) and spleen homogenates (right panel) from sham rats (closed bar) and rats that underwent a 3-hour extracorporeal circulation (open bar).

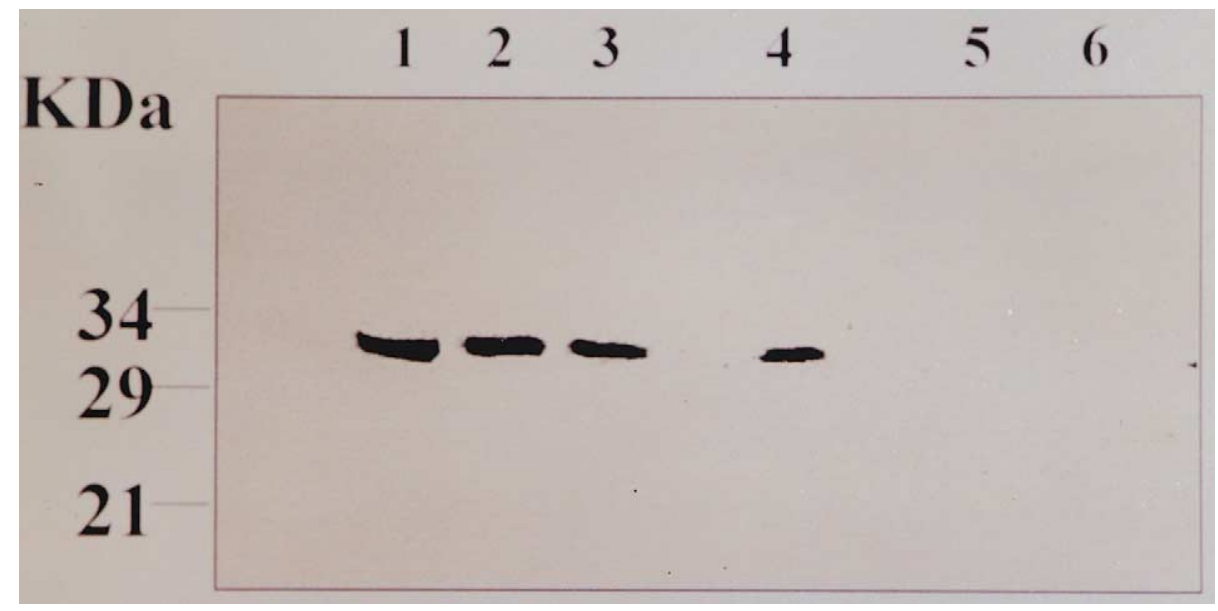

Figure 4. Representative Western blotting products of $\mathrm{HO}$ detection in lung homogenates of rats that underwent either a 3-hour extracorporeal circulation (lanes 1, 2, and 3) or a sham procedure (lanes 5 and 6). Spleen homogenates (lane 4) were used as positive controls.

minute ECC. ${ }^{13}$ In the present study, we demonstrated an elevated HO1 isoform expression in postperfusion lung injury. Up-regulation of HO1 within lungs has been previously reported in other models of ALI such as those following endotoxemia or prolonged hyperoxia. ${ }^{9,20}$ Increases in HO1 mRNA and protein content have been detected within lungs 2 to 4 hours and 4 to 8 hours after systemic administration of endotoxin (a condition mimicking sepsis), respectively. Immunohistochemical studies have shown that up-regulation of $\mathrm{HO} 1$ occurred in various cells including air- way epithelial cells or inflammatory cells. Similar findings have been previously reported in hyperoxic lung injury ${ }^{20}$ and were also observed in our rat model of post-ECC ALI.

In our rat model of bypass, the pulmonary up-regulation of HO1 in post-ECC ALI was likely the consequence of multiple factors. In vitro and in vivo studies have demonstrated that cellular expression of $\mathrm{HO} 1$ can be dramatically induced by hemoglobin. ${ }^{21}$ Up-regulation of $\mathrm{HO} 1$ could reflect, at least in part, the exposure of pulmonary cells to free hemoglobin. Free hemoglobin might have originated from 


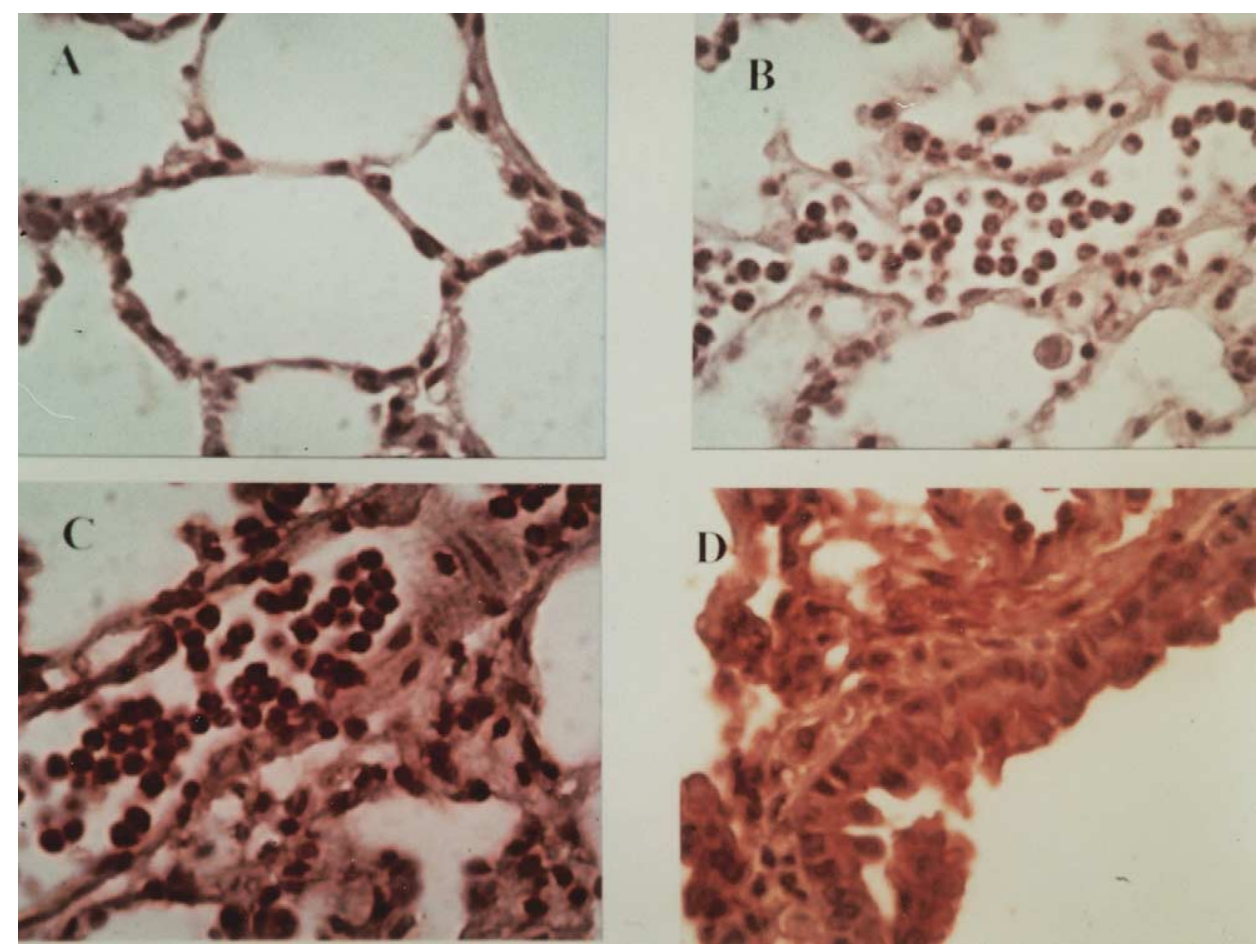

Figure 5. Immunohistochemistry of lung sections. Pulmonary H01 expression was not detected in sham rats (A). In rats from the extracorporeal circulation group, no staining was observed in lung specimens not exposed to the primary antibody (B). Neutrophils and macrophages (C and $D$ ) as well as some bronchiolar epithelial cells $(D)$ were stained positive for $\mathrm{HO1}$ in rats that underwent a 3-hour extracorporeal circulation. Original magnification $\times 1000$.

peripheral hemolysis, a well-known complication of prolonged bypass with roller pump as in our rat model, and from intrapulmonary hemorrhage, a common microscopic feature of post-ECC ALI. ${ }^{3,4}$ The blood concentrations of various cytokines have also been shown to increase during and after ECC. ${ }^{22}$ Recently, Kotani and colleagues ${ }^{23}$ reported elevated concentrations of tumor necrosis factor, interleukin 6, and interleukin 8 in patients' bronchoalveolar lavage fluid obtained after ECC. Thus, the systemic and pulmonary production of proinflammatory cytokines might also be responsible for the up-regulation of $\mathrm{HO}$ in postECC ALI. ${ }^{7}$

There is a large growing body of evidence suggesting that induction of HO1 expression may confer protection to cells and tissues against oxidative injury. Recently, Yamada and colleagues ${ }^{24}$ observed that up-regulation of HO1 (by hemin or interleukin 1- $\beta$ ) prevented the hydrogen peroxideinduced increase in permeability of human tracheal epithelium in culture. This protective effect was abolished by competitive inhibitors of HO. Otterbein and associates ${ }^{25}$ also reported that overexpression of $\mathrm{HO} 1$ achieved by gene transfer in rat lungs improved survival and attenuated the lung injury secondary to prolonged hyperoxia. The functional significance of HO1 up-regulation in post-ECC acute lung injury is the subject of an ongoing experimental study in our laboratory.

It has been speculated that the protection conferred by HO1 up-regulation could be related to the byproducts of heme degradation. Bilirubin has potent antioxidant properties in vitro. ${ }^{26}$ Hayashi and colleagues ${ }^{27}$ described a bilirubin-induced inhibition of neutrophil adhesion to the endothelium during an oxidative vascular injury. Ferritin, the synthesis of which can be induced by an HO-dependent iron release, ${ }^{28}$ has also been demonstrated to be a potent antioxidant. ${ }^{29}$ Finally, $\mathrm{CO}$ (usually considered as a potentially toxic waste product of metabolism) has been shown to have a major anti-inflammatory action. Otterbein and cowork$\mathrm{ers}^{30}$ recently demonstrated that exogenous $\mathrm{CO}$ at low concentration (50-500 ppm) attenuated posthyperoxia ALI by stimulation of the p38-mitogen-activated protein kinase pathway. Fujita and colleagues ${ }^{31}$ also reported a protective effect of $\mathrm{CO}$ in ischemia-reperfusion lung injury through derepression of fibrinolysis. The role of the increased endogenous $\mathrm{CO}$ production that we observed in our rat model of bypass should be investigated.

In summary, we demonstrated that a 3-hour ECC in rats was responsible for an ALI, which was associated with an increased expression of HO1. We also observed an increase 
in exhaled $\mathrm{CO}$ concentration, reflecting an elevated endogenous $\mathrm{CO}$ production, possibly secondary to an exaggerated hemolysis. The determination of the physiological significance of the increased $\mathrm{HO} 1$ expression in lungs following ECC will require further studies.

We are grateful to Professor Gilles Chatelier for his statistical reviewing and to Sophie Goyer for her technical assistance.

\section{References}

1. Christenson JT, Aeberhard J-M, Badel P, et al. Adult respiratory distress syndrome after cardiac surgery. Cardiovasc Surg. 1996;4:1521.

2. Asimakopoulos G, Taylor KM, Smith PL, Ratnatunga CP. Prevalence of acute respiratory distress syndrome after cardiac surgery. $J$ Thorac Cardiovasc Surg. 1999;117:620-1.

3. Ratliff NB, Young WG, Hackel DB, Mikat E, Wilson JW. Pulmonary injury secondary to extracorporeal circulation. An ultrastructural study. J Thorac Cardiovasc Surg. 1973;65:425-32.

4. Anyanwu E, Dittrich H, Gieseking R, Enders H-J. Ultrastructural changes in the human lung following cardiopulmonary bypass. Basic Res Cardiol. 1982;77:309-22.

5. Marilena G. New physiological importance of two classic residual products: carbon monoxide and bilirubin. Biochem Mol Med. 1997; 61:136-42.

6. Coburn RF. Endogenous carbon monoxide production and body CO stores. Acta Med Scand. 1968;472:S269-82.

7. Maines MD. The heme oxygenase system: a regulator of second messenger gases. Апnи Rev Pharmacol Toxicol. 1997;37:517-54.

8. Applegate LA, Luscher P, Tyrell RM. Induction of heme oxygenase: a general response to oxidant stress in cultured mammalian cells. Cancer Res. 1991;51:974-8.

9. Choi AMK, Alam J. Heme oxygenase 1: function, regulation, and implication of a novel stress-inducible protein in oxidant-induced lung injury. Am J Respir Cell Mol Biol. 1996;15:9-19.

10. Fabre O, Zegdi R, Vincentelli A. A recovery model of partial cardiopulmonary bypass in the rat. Perfusion. 2001;16:215-20.

11. Convention européenne sur la protection des animaux vertébrés utilisés à des fins expérimentales ou à d'autres fins scientifiques. Journal Officiel des Communautés Européennes. L222/9 à L222/37. August 24, 1999.

12. Tenhunen R, Marver HS, Schmid R. The enzymatic conversion of heme to bilirubin by microsomal heme oxygenase. Biochemistry. 1968;61:748-55.

13. Zegdi R, Fabre O, Cambillau M, et al. Exhaled nitric oxide does not reflect the severity of acute lung injury. An experimental study in a rat model of extracorporeal circulation. Crit Care Med. 2002;30:2096102.

14. Coburn RF, Forster RE, Kane PB. Considerations of the physiological variables that determine the blood carboxyhemoglobin concentration in man. J Clin Invest. 1965;44:1899-910.
15. Coburn RF, Williams WJ, White $\mathrm{P}, \mathrm{Kahn} \mathrm{S}$. The production of carbon monoxide from hemoglobin in vivo. J Clin Invest. 1967;46:346-56.

16. Stevenson DK, Ostrander CE, Johnson JD. Effect of erythrocyte destruction on the pulmonary excretion rate of carbon monoxide in adult male Wistar rats. J Lab Clin Med. 1979;94:649-54.

17. Zayasu K, Sekizawa K, Okinaga S, Yamaya M, Ohrui T, Sasaki H. Increased carbon monoxide in exhaled air of asthmatic patients. Am J Respir Crit Care Med. 1997;156:1140-3.

18. Horvath I, Loukides S, Wodehouse T, Kharitonov SA, Cole PJ, Barnes PJ. Increased levels of exhaled carbon monoxide in bronchiectasis: a new marker of oxidative stress. Thorax. 1998;53:867-70.

19. Paredi P, Kharitonov SA, Leak D, et al. Exhaled ethane is elevated in cystic fibrosis and correlates with carbon monoxide levels and airway obstruction. Am J Respir Crit Care Med. 2000;162:369-73.

20. Lee PJ, Alam J, Sylvester SL, Inamdar N, Otterbein LE, Choi AMK. Regulation of heme oxygenase-1 expression in vivo and in vitro in hyperoxic lung injury. Am J Respir Cell Mol Biol. 1996;14:556-68.

21. Otterbein LE, Sylvester SL, Choi AMK. Hemoglobin provides protection against lethal endotoxemia in rats: the role of heme oxygenase-1. Am J Respir Cell Mol Biol. 1995;13:595-601.

22. Wan S, DeSmet JM, Barvais L, Goldstein M, Vincent JL, LeClerc JL. Myocardium is a major source of proinflammatory cytokines in patients undergoing cardiopulmonary bypass. J Thorac Cardiovasc Surg. 1996;112:806-11.

23. Kotani N, Hashimoto H, Sessler DI, et al. Neutrophil number and interleukin-8 and elastase concentrations in bronchoalveolar lavage fluid correlate with decreased arterial oxygenation after cardiopulmonary bypass. Anesth Analg. 2000;90:1046-51.

24. Yamada N, Yamaya M, Okinaga S, et al. Protective effects of heme oxygenase-1 against oxidant-induced injury in the cultured human tracheal epithelium. Am J Respir Cell Mol Biol. 1999;21:428-35.

25. Otterbein LE, Kolls JK, Mantell LL, Cook JL, Alam J, Choi AMK. Exogenous administration of heme oxygenase- 1 by gene transfer provides protection against hyperoxia-induced lung injury. J Clin Invest. 1999; 103:1047-54.

26. Stocker R, Yamamoto Y, McDonagh AF, Glazer AN, Ames BN. Bilirubin is an antioxidant of possible physiological importance. Science. 1987;235:1043-6.

27. Hayashi S, Takamiya R, Yamaguchi $T$, et al. Induction of heme oxygenase-1 suppresses venular leucocyte adhesion elicited by oxidative stress. Role of bilirubin generated by the enzyme. Circ Res. 1999;85:663-71.

28. Vile GF, Tyrell RM. Oxidative stress resulting from ultraviolet A irradiation of human skin fibroblasts leads to a heme oxygenasedependent increase in ferritin. J Biol Chem. 1993;268:14678-81.

29. Balla G, Jacob HS, Balla J, et al. Ferritin: a cytoprotective antioxidant stratagem of endothelium. J Biol Chem. 1992;267:18148-53.

30. Otterbein LE, Bach FH, Alam J, et al. Carbon monoxide has antiinflammatory effects involving the mitogen-activated protein kinase pathway. Nat Med. 2000;6:422-8.

31. Fujita T, Toda K, Karimova A, et al. Paradoxical rescue from ischemic lung injury by inhaled carbon monoxide driven by derepression of fibrinolysis. Nat Med. 2001;7:598-604. 